\title{
Artigo Original / Original Paper \\ Convolvulaceae de Pernambuco, Brasil I: \\ Camonea, Daustinia, Distimake e Operculina
}

Convolvulaceae from Pernambuco, Brazil: Camonea, Daustinia, Distimake and Operculina

\author{
Deibson Pereira Belo ${ }^{1,2,3}$, Silmara Cecília Nepomuceno ${ }^{1}$, Juliana Aureliano de Alencar Monteiro Lourenço ${ }^{1}$ \\ \& Maria Teresa Buril ${ }^{1}$
}

\begin{abstract}
Resumo
O presente trabalho é a primeira contribuição de uma série de estudos sobre a diversidade de Convolvulaceae em Pernambuco (PE). Aqui são tratadas as espécies dos gêneros Camonea (1 sp), Daustinia (1 sp), Distimake (7 spp) e Operculina (2 spp). Para isto, foram realizadas expedições de campo entre os anos de 2014 a 2018 , além de consultas aos principais herbários da região. A ocorrência dessas espécies nos diferentes domínios fitogeográficos do estado é discutida. Distimake flagellaris e D. tomentosus se configuram como novos registros. São apresentadas chaves de identificação para os gêneros de Convolvulaceae ocorrentes em PE e de identificação para as espécies abordadas neste tratamento, além de descrições, comentários taxonômicos e de distribuição e ilustrações.
\end{abstract}

Palavras-chave: florística, jitirana, morfologia, taxonomia, trepadeiras.

\begin{abstract}
This work is the first comprehensive contribution from a series of studies about diversity of Convolvulaceae in Pernambuco (PE). Here are treated the genera Camonea (1 sp), Daustinia (1 sp), Distimake (7 spp) and Operculina (2 spp). The study was conducted through field expeditions between 2014 and 2018, and visit to the main herbaria of the region. The distribution of these species among different vegetation domains in the state is discussed. Distimake flagellaris and D. tomentosus are new records. An identification key to the genera of Convolvulaceae present in PE, a key for species treated here, descriptions, taxonomic and distribution comments and illustrations are presented.
\end{abstract}

Key words: floristic, jitirana, morphology, taxonomy, vines.

\section{Introdução}

Convolvulaceae compreende cerca de 1.900 espécies em 58 gêneros, é cosmopolita, porém, com maior representatividade na região tropical (Staples 2010). No Brasil, são conhecidas 430 espécies, das quais 194 são endêmicas, presentes em todos os domínios fitogeográficos, mas são predominantes em ambientes com maior incidência luminosa, como o Cerrado, Caatinga e bordas de mata (BFG 2018).

De acordo com a hipótese filogenética mais recente (Stefanovic et al. 2003), a família está dividida em 12 tribos (Aniseieae, Cardiochlamyeae, Convolvuleae, Cresseae, Cuscuteae, Dichondreae, Erycibeae, Humbertieae, Ipomoeeae, Jacquemontieae, Maripeae e Merremieae). Entre os principais problemas taxonômicos apontados por esse estudo filogenético constam grupos com baixo suporte, sem sinapomorfias morfológicas evidentes, além de gêneros com circunscrição imprecisa.

Entre essas questões levantadas a partir do trabalho de Stefanovic et al. (2003), a tribo Merremiae, que em sua circunscrição tradicional (Staples \& Brummit 2007) emergiu como polifilética

\footnotetext{
${ }^{1}$ Universidade Federal Rural de Pernambuco, Depto. Botânica, Lab. Sistemática de Angiospermas, R. Dom Manuel de Medeiros s/n, Dois Irmãos, 52171-900, Recife, PE, Brasil.

${ }^{2}$ ORCID: < https://orcid.org/0000-0001-6618-3223>

${ }^{3}$ Autor para correspondência: deibson.belo@yahoo.com.br
} 
e foi alvo de estudos filogenéticos posteriores (Simões et al. 2015), que verificaram uma dissolução da tribo em seis diferentes clados. A partir desses resultados foram propostas novas combinações e os gêneros da extinta tribo, por não apresentarem uma relação filogenética clara, foram considerados como incertae sedis (Simões \& Staples 2017).

Dentre estes, se destaca o gênero Merremia Dennst. ex Endl., polifilético, que teve a maioria de suas espécies combinadas para outros gêneros: Camonea Raf., Decalobanthus Ooststr., Distimake Raf. e Xenostegia DF Austin. Em sua atual circunscrição, Merremia s.s. tem distribuição paleotropical, e destes, apenas Camonea e Distimake apresentam espécies ocorrentes no Brasil (Simões \& Staples 2017).

Além de Camonea e Distimake, entre os outros gêneros que hoje não estão subordinados a nenhuma tribo de Convolvulaceae e que ocorrem no Brasil estão Operculina Silva-Manso e Daustinia Buril \& A.R. Simões. O primeiro é claramente monofilético e apresenta como sinapomorfia a cápsula deiscente por uma circuncisão operculoide. Daustinia é um gênero monoespecífico, endêmico do Brasil, e que foi recentemente estabelecido para alocar duas espécies anteriormente circunscritas em Jacquemontia (Buril et al. 2014, 2015). Na filogenia de Simões et al. (2015), Daustinia emergiu como grupo irmão de Ipomoeae, mas claramente é diferenciada pelos grãos de pólen psilados ao invés de equinados.

Os estudos sobre a diversidade desse grupo no nordeste do país se limitam a citações em floras locais: (Buril \& Alves 2011; Buril et al. 2013; Delgado-Junior et al. 2014; Nepomuceno et al. 2016). Paras as outras regiões do país, podem ser citados o tratamento taxonômico de Merremia para a região sul (Ferreira \& Miotto 2013) e para o estado de São Paulo (Petrongari 2016); e a publicação de um novo registro de ocorrência de Operculina pteripes (G.Don) O'Donell para o Brasil (Moreira et al. 2016). Todos os gêneros aqui tratados apresentam potencial econômico e medicinal. Apesar de diversas espécies de Distimake serem conhecidas como "ervas-daninhas", algumas apresentam potencial ornamental, medicinal e alimentício (ex: Distimake dissectus (Jacq.) Simões \& Staples ornamental; Austin 2007), e também são utilizadas para a produção de feno em áreas áridas no Brasil (ex: Distimake aegyptius (L.) Simões \& Staples (= Merremia aegyptia (L.) Urban); Lacerda et al. 2015). Ainda, Operculina macrocarpa (L.) Urb., popularmente conhecida como "batata-de-purga", tem raízes tuberosas, amiláceas, são utilizadas para fins medicinais (Lorenzi e Matos 2002).

Neste contexto, o presente trabalho propõese a ampliar o conhecimento sobre a família no Nordeste do país, fornecendo chave de gênero para as espécies ocorrentes em Pernambuco e o tratamento taxonômico de Camonea, Daustinia, Distimake e Operculina. Este trabalho é a primeira contribuição para uma série de monografias sobre a diversidade de Convolvulaceae no estado.

\section{Material e Métodos}

Área de estudo

Pernambuco localiza-se no centro-leste da Região Nordeste, com uma área de $98.311 \mathrm{~km}^{2} \mathrm{e} 185$ municípios. O clima é tropical no litoral e semiárido no interior. Seu relevo no litoral é planície; na região central é cortado pelo Planalto da Borborema; e há depressões de leste a oeste. Sua vegetação é composta por mangues no litoral, Floresta Tropical na zona da mata, e Caatinga na região agreste ao sertão (Andrade-Lima 1960).

\section{Levantamento dos dados}

O presente trabalho foi realizado através de expedições botânicas no estado, no período de 2014 a 2018. As coletas foram realizadas de acordo com a metodologia de Mori et al. (1985), e todo material coletado foi incorporado ao Herbário Vasconcelos Sobrinho (PEUFR). Foram ainda consultados os acervos dos herbários ASE, EAC, HESBRA (Herbário do Semiárido Brasileiro, não indexado), HST (Herbário Sérgio Tavares, não indexado), HUEFS, HVASF, IPA, JPB, MAC e UFP (Thiers, continuamente atualizado). As identificações foram realizadas a partir de consulta à literatura específica (Buril et al. 2014, 2015; Ferreira \& Miotto 2013; O’Donell 1941; Simões \& Staples 2017) e tratamentos florísticos para a região supracitados, além de comparação com material identificado por especialistas e espécimes typus disponíveis on line (JSTOR 2016). As descrições seguem a terminologia proposta por Harris \& Harris (2001). Os comentários de distribuição no estado seguem os dados disponibilizados nas etiquetas dos herbários e observações em campo, e no Brasil segue a Flora do Brasil (BFG 2018). O material examinado foi selecionado buscando representar a amplitude de distribuição da espécie no estado, somado à representatividade morfológica das espécies. Para as espécies de Distimake e Camonea, são citados como sinônimos relevantes os nomes ainda utilizados na maioria das coleções científicas. 
Considerando que o presente trabalho é a primeira monografia de uma série de estudos sobre a diversidade de Convolvulaceae em Pernambuco, apresentamos uma chave de identificação para os gêneros ocorrentes no estado, elaborada com base no material estudado pelo grupo de pesquisa bem como com auxílio de referências bibliográficas - Convolvulaceae da Microrregião do Alto Capibaribe, PE, Brasil (Nepomuceno et al. 2016); Convolvulaceae da região do Cariri Paraibano, PB, Brasil (Buril et al. 2013); Convolvulaceae do Parque Nacional do Catimbau, Pernambuco, Brasil (Delgado-Junior et al. 2014); O gênero Merremia na região Sul do Brasil (Ferreira \& Miotto 2013); Flora do Brasil (BFG 2018)Embora os gêneros aqui tratados não apresentem uma relação filogenética clara, morfologicamente compartilham os estiletes inteiros com estigmas biglobosos, anteras geralmente retorcidas após a antese, corola geralmente amarela ou branca e grãos de pólen psilados. Apesar de algumas dessas características provavelmente serem homoplásicas (anteras retorcidas, por exemplo, são encontradas em espécies de Ipomoea que não ocorrem em PE), podem ser consideradas úteis para o reconhecimento das espécies destes quatro gêneros que ocorrem no estado.

\section{Resultados e Discussão}

Foram registradas para Pernambuco sete espécies de Distimake, duas de Operculina, e uma espécie para cada um dos gêneros Camonea e Daustinia. A maioria das espécies possui ampla distribuição e ocorrem em diferentes formações vegetacionais, apesar de geralmente serem frequentemente associadas a ambientes florestais. Camonea umbellata (L.) Simões \& Staples e D. aegyptius (L.) Simões \& Staples são as espécies mais comuns e normalmente ocorrem em área com influência antrópica. Distimake dissectus (Jacq.) Simões \& Staples e D. flagellaris (Choisy) Simões \& Staples, este último um novo registro para o estado, foram encontradas apenas em ambientes de Mata Atlântica, assim como D. tuberosus (L.) Simões \& Staples, apesar de termos coletado um indivíduo em ambiente de Caatinga (município de Serra Talhada); contudo, por ser uma espécie utilizada como ornamental, é possível que sementes tenham sido introduzidas na região. Outro caso de ampliação de distribuição pouco provável foi a de D. tomentosus (Choisy) Petrongari \& Sim.-Bianch., uma espécie conhecida como endêmica de áreas de cerrado, foi registrada para a Mata Atlântica por um voucher coletado na Mata de Dois Irmãos (em Recife), depositado no herbário PEUFR. Um segundo voucher proveniente da Mata do Cabo de Santo Agostinho estava registrado nos bancos de dados do herbário IPA, porém o espécime não foi localizado. Apesar de termos segurança na identificação do espécime analisado, acreditamos que esta distribuição é pouco provável e a espécie pode ter chegado através de vias não naturais. Realizamos coletas em ambas as áreas e nenhum indivíduo foi encontrado. No entanto, como não foi possível confirmar o histórico da presença de D. tomentosus na Mata Atlântica pernambucana, decidimos incluí-la neste tratamento.

\section{Chave de identificação dos gêneros de Convolvulaceae ocorrentes em Pernambuco, Brasil}

1. Plantas holoparasitas Cuscuta

1'. Plantas não-parasitas 3

2. Caule alado; cápsula circuncisa apical, operculoide ................................................ 4. Operculina

2'. Caule não alado (exceto em Ipomoea pterocaulis, mas nesse caso, as flores são róseas, e não amarelas ou brancas como em Operculina); cápsula loculicida ou raro indeiscente.

3. Plantas com tricomas estrelados; lobos estigmáticos ovais-planos. Jacquemontia

3'. Plantas glabras ou com tricomas simples ou malpighiáceos (estrelados em D. tomentosus, mas nesse caso, os lobos estigmáticos são globosos); lobos estigmáticos filiformes, clavados ou globosos

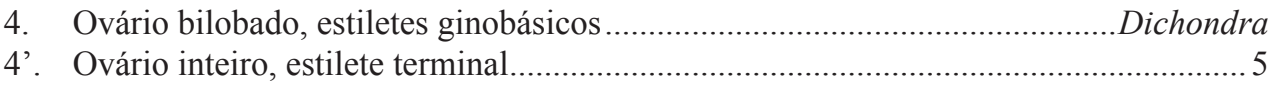

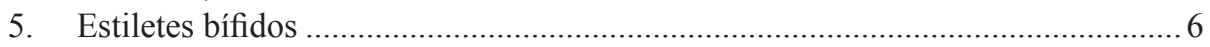

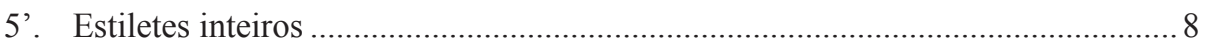

6. Ervas ou subarbustos, eretos, decumbentes ou prostrados, nunca trepadeiras; estigmas bífidos filiformes ou clavados ......................................... Evolvulus

6'. Trepadeiras; estigmas não divididos, globosos ........................................... 7 


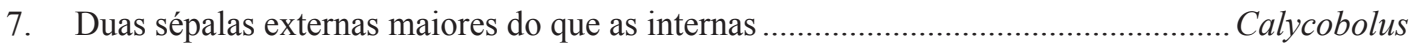

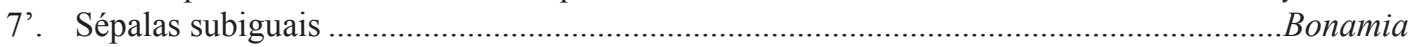

8. Projeção espinescente na axila (não confundir com ramos aculeados)................. Camonea

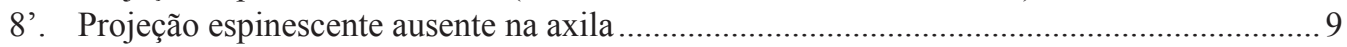

9. Duas sépalas externas cordiformes, maiores que as internas ...............................Aniseia

9'. Sépalas de várias formas, mas nunca cordiformes ...................................................... 10

10. Inflorescências capituliformes; corola amarela .................................. 2. Daustinia

10'. Inflorescências variáveis, mas nunca capituliformes (se capituliformes, a corola rosa), flores brancas, amarelas com fauce vinácea, azuis, roxas ou vermelhas .. 11

11. Corola branca ou amarela; anteras geralmente retorcidas após a antese, grãos de pólen psilados

3. Distimake

11'. Corola rósea, azul, roxa ou vermelhas, branca ou amarela com fauce vinácea; anteras geralmente retas após a antese, grãos de pólen equinados....Ipomoea

\section{Camonea Raf.}

1.1. Camonea umbellata (L.) Simões \& Staples, Sp. P1. 155. 1753. Fig. 1a

Trepadeira herbácea; ramos não alados, lisos, glabros a esparsamente pilosos, entrenós 5-28 cm compr.; látex ausente. Folhas simples, inteiras, $3-8,7 \times 1,4-8,5 \mathrm{~cm}$, largo-elípticas a elípticas, margem inteira, base cordada, ápice agudo, glabra em ambas as faces; 6 a 10 pares de nervuras secundárias; pecíolo 0,7-4 cm compr., glabro, com projeção espinescente na axila. Inflorescência cimeira umbeliforme, multiflora; pedúnculo ca. $4 \mathrm{~cm}$ compr., glabro; pedicelo 1-1,5 cm compr., glabro; brácteas ausentes. Sépalas iguais em forma, externas pouco maiores que as internas; externas $1-1,1 \times 0,7-0,8 \mathrm{~cm}$, ovadas, base truncada, ápice mucronado, glabras, internas $0,9-1,1 \times 0,7-0,8 \mathrm{~cm}$. Corola amarela, ca. $4 \mathrm{~cm}$ compr., infundibuliforme, glabra. Estames com anteras retorcidas após a antese. Estilete inteiro, terminal, estigmas biglobosos, ovário 2-locular, 4-ovulado. Cápsula loculicida, ca. $1,2 \mathrm{~cm}$ compr.; sementes ca. 0,6 cm compr., velutinas.

Material examinado selecionado: Igarassu, Usina São José, 16.X.2002, fl. e fr., G.J. Bezerra et al. 47 (PEUFR). Ilha de Fernando de Noronha, Ponta da Sapata, 17.X.2003, fl. e fr., A.M. Miranda 4225 (HST). Recife, UFPE, 17.X.1995, fl., A.S.F. Castro 68 (EAC).

É amplamente distribuída nas Américas e na Ásia (Simões \& Staples 2017) e no Brasil pode ser encontrada em praticamente todo o território. Em Pernambuco é frequentemente encontrada em áreas sob influência antrópica, sendo comuns em na Mata Atlântica. Pode ser reconhecida pelo seguinte conjunto de caracteres: folhas simples, inteiras, de base cordada, e uma projeção espinescente na base do pecíolo (característica sinapomórfica do gênero) (Simões \& Staples 2017), e inflorescência umbeliforme com flores amarelas. Floresce de maio a dezembro, e frutifica entre agosto a dezembro.

Sinônimo relevante: Merremia umbellata (L.) Hallier $\mathrm{f}$.

\section{Daustinia Buril \& Simões}

2.1. Daustinia montana (Moric.) Buril \& Simões, Pl. Nouv. Amer. 44, t. 30. $1838 . \quad$ Fig. 1b

Trepadeira herbácea; ramos não alados, lisos, seríceos, entrenós 1,6-11 cm compr.; látex presente. Folhas simples, inteiras a trilobada, 1,8-5,6 $\times 1,3-3,8 \mathrm{~cm}$, margem denteada, base truncada, ápice obtuso a redondo e mucronado, indumento seríceo em ambas as faces; 5 a 10 pares de nervuras secundárias. Pecíolo 0,46-3,6 cm compr., viloso, sem projeção espinescente na axila. Inflorescência cimeira capituliforme, ca. 7 flores; pedúnculo 2,5$6,2 \mathrm{~cm}$ compr., viloso; pedicelo $0,3-0,5 \mathrm{~cm}$ compr., viloso; brácteas $1,1-1,6 \times 0,5-0,8 \mathrm{~cm}$, elípticas; bracteólas $0,4-1 \mathrm{~cm}$ compr., lanceoladas. Sépalas desiguais, externas $0,5-0,8 \times 0,2-0,4 \mathrm{~cm}$, elípticas, base truncada a cuneada, ápice agudo a acuminado, internas $0,3-0,6 \times 0,1-0,2 \mathrm{~cm}$, lanceoladas, base truncada, ápice acuminado. Corola amarela, $0,8-1,3$ $\mathrm{cm}$ compr., infundibuliforme, com tubo curto, glabra. Estames com anteras retorcidas após a antese. Estilete inteiro, terminal, estigmas biglobosos, ovário 2-locular, 4-ovulado. Cápsula loculicida, ca. $0,5 \mathrm{~cm}$ compr; sementes ca $0,4 \mathrm{~cm}$ compr, vilosas. Material examinado selecionado: Búqque, entrada da Vila do Catimbau, 9.V.2015, fl. e fr., G.C. Delgado Junior et al. 811 (PEUFR). Goiana, 30.V.1935, fl. e fr., B. Pickel (IPA - 4649). Igarassu, Engenho Água Branca, 2.V.1998, fl., M.F. Lucena 454 (PEUFR).

Endêmica do Brasil, presente em áreas de Caatinga, Cerrado e Tabuleiros (Mata Atlântica), do Piauí ao Rio de Janeiro. Em Pernambuco é uma 


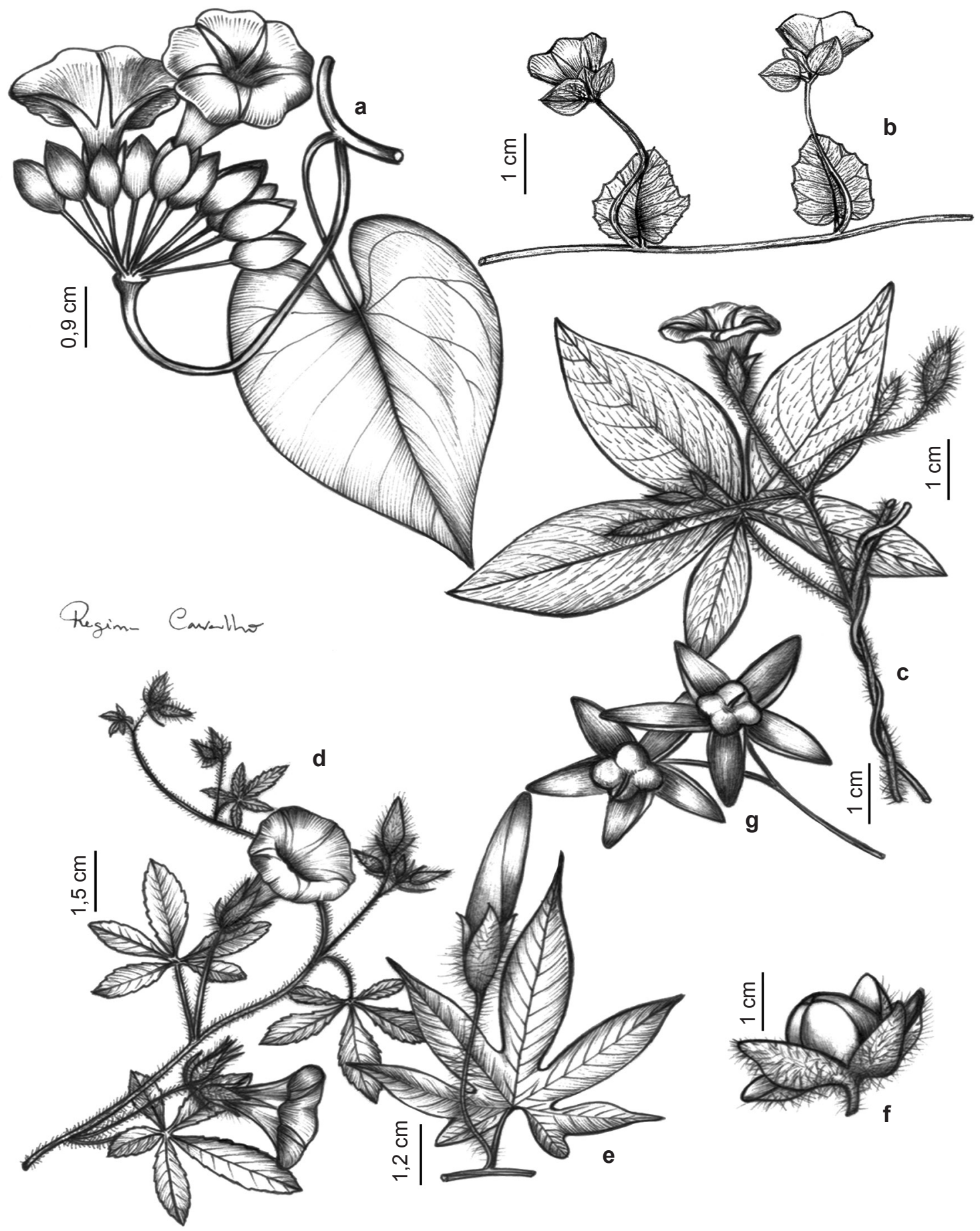

Figura 1 - a. Camonea umbellata - inflorescência. b. Daustinia montana - ramo florífero. c. Distimake aegyptius - ramo florífero. d. Distimake cissoides - ramo florífero. e-f. Distimake dissectus - e. ramo florífero; f. fruto. g. Distimake macrocalyx - fruto.

Figure 1 - a. Camonea umbellata - inflorescence. b. Daustinia montana - fertile branch. c. Distimake aegyptius - fertile branch. d. Distimake cissoides - fertile branch. e-f. Distimake dissectus - e. fertile branch; f. fruit. g. Distimake macrocalyx - fruit. 
espécie pouco frequente, sendo encontradas poucas populações em matas de restinga e na Caatinga. Apesar do intenso polimorfismo foliar encontrado na espécie, os indivíduos encontrados em Pernambuco apresentam folhas geralmente inteiras (não lobadas) e serreadas, seríceas em ambas as faces, além das inflorescências cimeiras capituliformes com muitas brácteas, e flores amarelas. Floresce entre os meses de maio a novembro, frutificando entre julho a novembro.

Sinônimo relevante: Jacquemontia montana (Moric.) Meisn.

\section{Distimake Raf.}

Trepadeiras, raramente subarbustos eretos ou prostrados, ramos não alados, glabros ou com indumento, tricomas tectores simples, raro estrelados ou glandulares. Folhas simples ou compostas, inteiras ou lobadas, com margem inteira ou serreada. Pecíolo sem projeção espinescente na axila. Inflorescências cimeiras monocasiais 1-multi-floras, pedunculadas. Sépalas iguais ou desiguais, glabras ou indumentadas. Corola branca ou amarela, infundibuliforme. Estames com anteras retorcidas após a antese, estilete terminal, ovário 2-locular, 4-ovulado. Cápsula loculicida.

\section{Chave de identificação das espécies de Distimake}

1. Arbustos eretos; ramos com tricomas estrelados

3.6. Distimake tomentosus

1'. Trepadeiras ou subarbustos prostrados; ramos glabros ou com tricomas simples ou glandulares .......2

2. Folhas simples.....

2'. Folhas compostas

3.3. Distimake dissectus

3. Ramos e pecíolos hirsutos, corola branca

3.7. Distimake tuberosus

3'. Ramos e pecíolos glabros ou puberulentos, corola amarela

4. Ramos e folíolos glandulares ... 5

4'. Ramos e folíolos glabrescentes a hirsutos.

5. Folíolos com margem serreada 6

5'. Folíolos com margem inteira.

3.2. Distimake cissoides

6. Ramos hirsutos....

3.4. Distimake flagellaris

6'. Ramos glabrescentes

3.1. Distimake aegyptius 3.5. Distimake macrocalyx

3.1. Distimake aegyptius (L.) Simões \& Staples, Sp. P1. 162. 1753.

Fig. 1c

Trepadeira herbácea; ramos lisos, hirsutos, tricomas dourados; entrenós 14,5-19,5 cm compr. Folhas 5-folioladas, folíolos 2,2-12 × 1,1-6 cm, elípticos, margem inteira, base cuneada, ápice acuminado, indumento hirsuto em ambas as faces; 5 a 9 pares de nervuras secundárias; pecíolo $0,7-15$ cm compr., hirsuto. Inflorescência cimeira dicasial, 1-multi-flora; pedúnculo 4,5-12 cm compr., hirsuto; pedicelo 0,8-3 cm compr., hirsutos; bractéolas $0,2-0,6 \mathrm{~cm}$ compr., lanceoladas. Sépalas desiguais, externas 1,7-2,1 × 0,7-0,9 cm, lanceolada, base truncada, ápice atenuado, hirsutas, internas 1-1,3 $\times 0,5-0,7 \mathrm{~cm}$, ovada, base arredondada, ápice agudo, glabras, não acrescentes no fruto. Corola branca, ca. 2,5 cm compr., infundibuliforme, hirsuta externamente. Cápsula ca. 1,5 cm compr.; sementes ca. $0,3 \mathrm{~cm}$ compr., glabras.

Material examinado selecionado: Cabo de Santo Agostinho, refúgio da vida silvestre matas do sistema Gurjaú, I.2016, fl., A.M. da Silva 19 (IPA). Mirandiba,
Fazenda Tigre, 17.IV.2007, fl. e fr., M.F. Lucena 259 (HUEFS). Serra Talhada, 2.VII.2016, fl., R.C.F.S. Gomes 2 (HESBRA).

Amplamente distribuída nas Américas (O’Donell 1941), e no Brasil é encontrada praticamente em todo o território e domínios fitogeográficos. Em Pernambuco é uma das espécies mais frequentes e comumente é encontrada em ambientes com influência antrópica. Pode ser identificada pelo seguinte conjunto de caracteres: folhas 5-folioladas, e indumento hirsuto, com tricomas dourados, nos ramos e nas sépalas. Floresce entre os meses de março a dezembro, e frutifica entre maio a dezembro.

Sinônimo relevante: Merremia aegyptia (L.) Urb.

3.2. Distimake cissoides (Lam.) Simões \& Staples, Tabl. Encycl. 1: 462. 1793.

Fig. 1d

Trepadeira herbácea; ramos lisos, hirsutos a glabrescentes, com tricomas glandulares; entrenós 2,5-15 cm compr. Folhas 5-6-folioladas, 
folíolos 2-4 × 0,4-1,8 cm, elípticos, tricomas glandulares, margem serreada, base atenuada a cuneada, ápice agudo a mucronado, indumento hirsuto a glabrescente em ambas as faces; 7 a 10 pares de nervuras secundárias; pecíolo 0,6-2,2 cm compr., pubescente. Inflorescência cimeira monocasial 1-flora; pedúnculo 1,7-2,3 cm compr., pubescente; pedicelo $0,2-0,8 \mathrm{~cm}$ compr., pubescente; bractéolas $0,6-1 \mathrm{~cm}$ compr., lanceoladas. Sépalas subiguais, externas 1,4-1,7 × $0,1-0,5 \mathrm{~cm}$, lanceoladas, base cuneada, ápice agudo, reflexos, tricomas glandulares, hirsutas, internas 1,4 $\times 0,5$, lanceoladas, base cuneada, ápice atenuado, tricomas glandulares, hirsutas. Corola branca com a fauce do tubo vinácea ou completamente branca, ca. 4 cm compr., infundibuliforme, glabra. Cápsula ca. $1 \mathrm{~cm}$ compr.; semente $0,4 \mathrm{~cm}$ compr., globosa. Material examinado selecionado: Floresta, rod. PE360, 9.VII.2008, fl. e fr., A.M. Miranda 5718 (MAC). Ibimirim, área de experimento, 2.VI.1982, M. Ataíde et al. 34 (IPA). Vitória de Santo Antão, Engenho Pombal, 19.IX.1998, fl. e fr., A. Laurênio 1360 (PEUFR).

Distribuída em toda a América (O’Donell 1941), no Brasil é registrada em todos os domínios fitogeográficos. Em Pernambuco ocorre predominantemente em áreas de Caatinga, mas também pode ser encontrada em ecótonos. Distingue-se das demais espécies do gênero pelos folíolos serreados e pela presença de tricomas glandulares. Floresce de março a dezembro, frutifica de junho a dezembro.

Sinônimo relevante: Merremia cissoides (Lam.) Hallier f.

3.3. Distimake dissectus (Jacq.) Simões \& Staples, Observ. Bot. 2: 4. tab. 28. $1767 . \quad$ Fig. 1e-f

Trepadeira herbácea; ramos lisos, hirsutos; entrenós 7-15 cm compr. Folhas simples, 5-9-lobadas, 8-10 × 10-13 cm, margem inteira, ápice mucronado, indumento hirsuto em ambas as faces; 5 a 8 pares de nervuras secundárias; pecíolo 3,5-6,5 cm compr., hirsuto. Inflorescência cimeira 1-3-flora; pedúnculo ca. $10 \mathrm{~cm}$ compr., hirsuto; pedicelo 3,5-4,0 cm compr., hirsuto; bractéolas ausentes. Sépalas desiguais, externas 2-2,4 $\times$ $0,6 \mathrm{~cm}$, ovais, base truncada, ápice arredondado, hirsutas, internas $1,8-2 \times 0,5-0,8 \mathrm{~cm}$, ovais, base truncada, ápice acuminado a mucronado, glabras, não acrescentes no fruto. Corola branca, 4-5,5 cm compr., infundibuliforme, glabra. Cápsula 1,2-2,4 cm compr.; semente 0,3-0,6 cm compr., glabra. Material examinado selecionado: Cabo de Santo Agostinho, Gaibu, 26.V.1933, fl., B. Pickel (IPA - 4689); 7.V.1968, fl. e fr., O.C. Lira 68201 (HUEFS).
Amplamente distribuída dos Estados Unidos à Argentina (O’Donell 1941), no Brasil é encontrada principalmente em ambientes florestais, na Amazônia e Mata Atlântica, em bordas de mata. Em Pernambuco é pouco frequente e restrita à Mata Atlântica. $\mathrm{Na}$ área de estudo pode ser comparada a D. aegyptius pela presença de indumento hirsuto, mas facilmente diferencia-se pelas folhas simples, lobadas (vs. 5-folioladas). Floresce e frutifica de maio a setembro.

Sinônimo relevante: Merremia dissecta (Jacq.) Hallier f.

3.4. Distimake flagellaris (Choisy) Simões \& Staples, Mém. Soc. Phys. Genève 8: 60 [Conv. Rar. 138] 1837.

Fig. 2a-b

Subarbusto prostrado; ramos lisos, glabros a glabrescentes, com tricomas glandulares; entrenós 2-6 cm compr. Folhas 5-folioladas, folíolos 3-7 × 3,5-10 cm, lineares, margem inteira, tricomas glandulares, base atenuada, ápice agudo, glabrescente a incano em ambas as faces; 6 a 10 pares de nervuras secundárias; pecíolo $0,2-0,5$ $\mathrm{cm}$ compr., glabrescente. Inflorescência cimeira 1-flora; pedúnculo 2,7-5,8 cm compr., glabrescente; pedicelo 0,5-1 cm compr., glabrescente; bractéolas 0,5-0,8 cm compr., oblanceoladas. Sépalas subiguais, externas $1,1-1,5 \times 0,5 \mathrm{~cm}$, ovais, base arredondada, ápice atenuado, incanos a pubescentes, internas $1,3-1,5 \times 0,5 \mathrm{~cm}$, ovais, base arredondada, ápice atenuado, incano. Corola branca, 2,8-3,8 cm compr., infundibuliforme, glabra. Cápsula ca. 0,4 cm compr.; sementes ca. $0,3 \mathrm{~cm}$ compr., vilosas.

Material examinado selecionado: Goiana, Engenho Carobé, 8.V.1995, fl. e fr., A. Lima (IPA - 7921). Itambé, tabuleiro silicoso de Itambé, 29.XII.1950, fl., A. Lima (IPA - 1988).

Endêmica do Brasil, é aqui reportada pela primeira vez em Pernambuco, ocorrendo em uma área de Mata Atlântica. É bastante semelhante a $D$. digitatus (Spreng.) Simões \& Staples, que não ocorre no estado, mas pode ser diferenciada pelo tipo indumento (D. digitatus, apresenta tricomas estrelados) (Ferreira \& Miotto 2013). Assemelha-se a D. cissoides pela presença de tricomas glandulares, mas os folíolos inteiros ( $v s$. serreados) as diferenciam. Pelo material analisado em herbário observou-se que a espécie no estado de Pernambuco floresce no mês de agosto.

Sinônimo relevante: Merremia flagellaris (Choisy) O'Donell. 


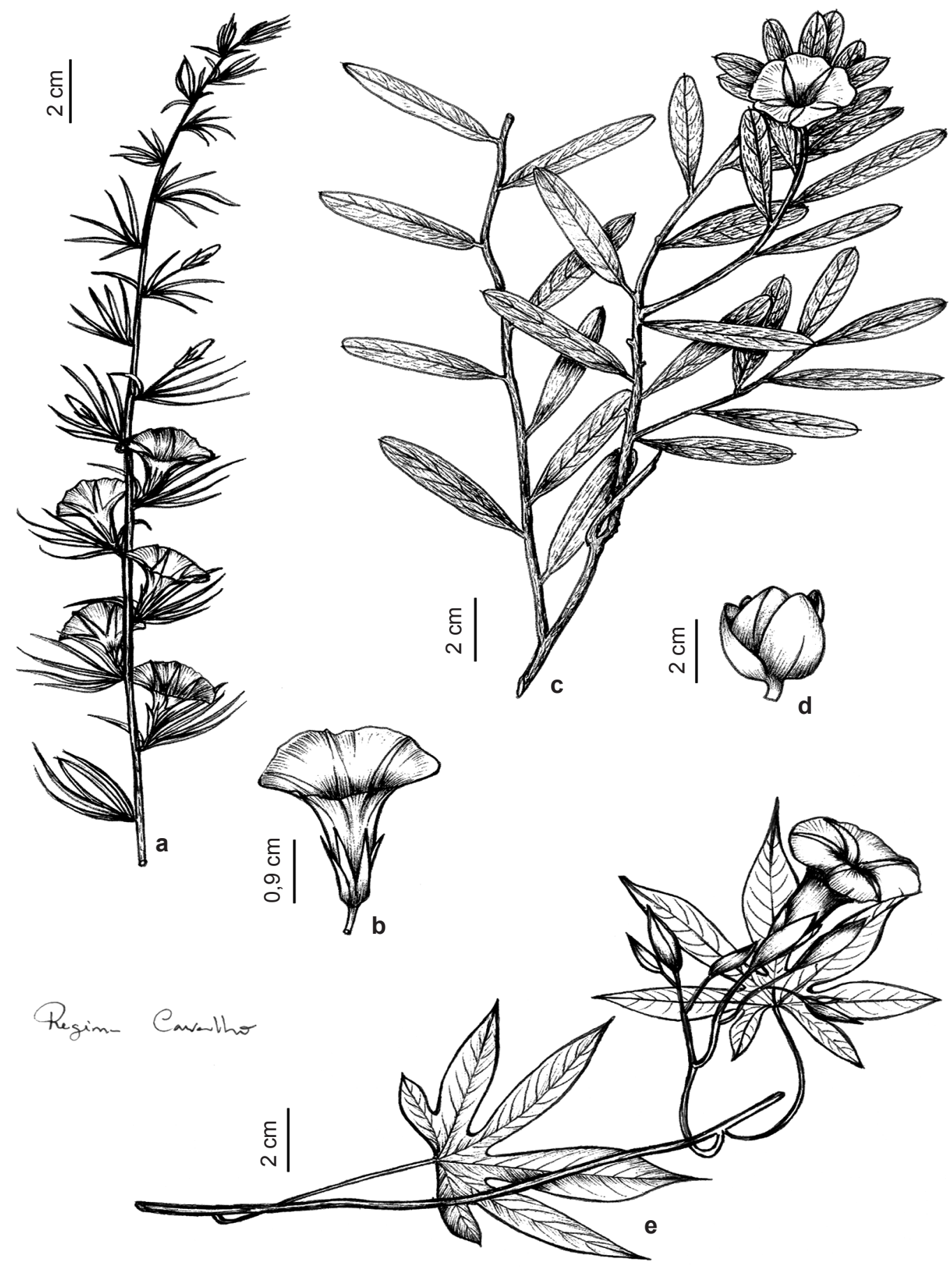

Figura 2 - a-b. Distimake flagellaris - a. ramo florífero; b. corola. c-d. Distimake tomentosus - c. ramo florífero; d. cálice no botão floral. e. Distimake tuberosus - ramo florífero.

Figure 2 - a-b. Distimake flagellaris - a. fertile branch; b. corolla. c-d. Distimake tomentosus - c. fertile branch; d. calyx on floral bud. e. Distimake tuberosus - fertile branch. 
3.5. Distimake macrocalyx (Ruiz \& Pav.) Simões \& Staples, Fl. Peruv. 2: 10. $1799 . \quad$ Fig. $1 \mathrm{~g}$

Trepadeira herbácea; ramos lisos, glabrescentes; entrenós 4,5-12 cm compr. Folhas 5-folioladas, folíolos 1,4-7,5 × 0,4-2,9 cm, elípticos a lanceolados, margem inteira, base atenuada a cuneada, ápice agudo a mucronado, glabra em ambas as faces; 5 a 14 pares de nervuras secundárias; pecíolo 1,6-4,8 cm compr., glabro. Inflorescência cimeira dicasial, multiflora; pedúnculo 3-10 cm compr., glabro; pedicelo 1,1$2,6 \mathrm{~cm}$ compr., glabro; bractéolas ausentes. Sépalas subiguais, externas $1,8-2 \times 0,9 \mathrm{~cm}$, oblongas a lanceoladas, base truncada, ápice mucronado, glabras, internas $2,1 \times 1,1 \mathrm{~cm}$, oblongas, base truncada, ápice mucronado, glabras, acrescentes no fruto. Corola branca com fauce amarela, 3,8-4 cm compr., infundibuliforme, glabra. Cápsula ca. 1 cm compr.; sementes ca. $0,4 \mathrm{~cm}$ compr., velutinas. Material examinado selecionado: Araripina, estação do IPA, 26.V.1995, fl., E. Sampaio et al. 471 (PEUFR). Bezerros, Serra Negra, 14.IV.2015, fl. e fr., D.S. Lucena 558 (UFP). Lagoa dos Gatos, RPPN Pedra D'Anta, 10.IX.2010, fl., J.L. Viana 20 (JPB).

Ocorre das Guianas à Argentina (O'Donell 1941), e no Brasil é amplamente distribuída em praticamente todo território. Em Pernambuco, são encontradas em áreas de borda de Mata Atlântica. Quando em flor, é facilmente reconhecida pelas sépalas membranáceas, oblongas, glabras, que são acrescentes no fruto. Floresce de maio a novembro e frutifica entre julho e novembro.

Sinônimo relevante: Merremia macrocalyx (Ruiz \& Pav.) O'Donell.

3.6. Distimake tomentosus (Choisy) Petrongari \& Sim.-Bianch., Mém. Soc. Phys. Genève 8(1): 55. 1838.

Fig. 2c-d

Subarbusto ereto; ramos lisos, indumento estrelado, denso; entrenós 5-17,5 cm compr. Folhas simples, $1,7-7 \times 0,6-1,2 \mathrm{~cm}$, elípticas, ovadas a oblanceoladas, margem inteira, base truncada a arredondada, ápice agudo, arredondado e mucronado, indumento estrelado denso, em ambas as faces; 5 a 7 pares de nervuras secundárias; pecíolo $0,2-0,5 \mathrm{~cm}$ compr., indumento estrelado, denso. Cimeira dicasial 1-3-flora; pedúnculo 0,5 cm compr., indumento estrelado, denso; pedicelo 0,5-1 cm compr., indumento estrelado, denso; bractéolas $0,1-0,3 \mathrm{~cm}$ compr. Sépalas subiguais, externas $0,3-0,6 \times 0,2-0,4 \mathrm{~cm}$, oblongas, base truncada, ápice agudo a obtuso, pubescentes a glabras, internas $0,6-0,7 \times 0,5 \mathrm{~cm}$, oblongas, base truncada, ápice obtuso, glabras. Cápsula ca. $1 \mathrm{~cm}$ compr.; sementes ca. 0,4-0,5 cm compr., velutinas. Material examinado selecionado: Recife, Dois Irmãos, 27.XII.1979, fl. e fr., I. Barreto et al. 07 (PEUFR).

É endêmica do Brasil, onde até então só apresentava registros nos estados da Bahia, Minas Gerais, São Paulo, Goiás, Distrito Federal, Mato Grosso, Mato Grosso do Sul e Paraná, exclusivamente em áreas de Cerrado. Apesar da distribuição disjunta pouco provável, confirmamos a identificação do espécime depositado no herbário PEUFR. Caso a ocorrência dessa espécie nas Matas de Dois Irmãos, em Recife, e no município de Santo Agostinho (IPA259, não localizado), seja natural, é possível que esteja extinta localmente, por se tratarem de áreas bastante fragmentadas e antropizadas. Além disso, foram realizadas visitas a estas localidades nos últimos anos e nenhum indivíduo foi encontrado.

Sinônimo relevante: Merremia tomentosa (Choisy) Hallier.

3.7. Distimake tuberosus (L.) Simões \& Staples, Sp. Pl. 160. 1753.

Fig. 2e

Trepadeira lenhosa; ramos lisos, glabros; entrenós 6,5-10,5 cm compr. Folhas simples, profundamente lobadas, 5-7 segmentos, 6-12 $\times$ 8-15 cm, lanceoladas a elípticas, margem inteira, ápice acuminado, glabra em ambas as faces; 6 a 12 pares de nervuras secundárias; pecíolo 10-13,5 cm compr., glabro. Inflorescência cimeira monocasial 1-flora; pedúnculo 10-15 cm compr., glabro; pedicelo $1-3 \mathrm{~cm}$ compr., glabro; bractéolas $0,2-0,5$ cm compr., lanceoladas, glabras. Sépalas desiguais, externas $1-3,5 \times 1,2-2 \mathrm{~cm}$, ovais, base truncada, ápice arredondado a mucronado, glabras, internas 1,1-3,2 $\times 0,7-1,4 \mathrm{~cm}$, elípticas, base truncada, ápice arredondado a mucronado, glabras, acrescentes no fruto. Corola amarela, 3,5-6 cm compr., campanulada, glabra. Cápsula ca. 0,6 cm compr., com pericarpo membranáceo; sementes $2-2,5 \mathrm{~cm}$ compr., pubescentes.

Material examinado selecionado: Serra Talhada, estrada após a UAST, 27.III.2017, fl., D. Belo et al. 17 (PEUFR). Recife, Jardim Botânico do Recife, 18.VIII.2011, fl. e fr., E.D. Mendonça (JPB - 48377); Parque Dois Irmãos, 15.IX.2000, fl., F.V. Silva (HST - 15148).

Ocorre dos Estados Unidos ao Brasil (O’Donell 1941), onde está registrada para a Mata Atlântica do nordeste ao sudeste. Apesar de ser uma espécie típica de Mata Atlântica, foi coletado um espécime no município de Serra Talhada (Caatinga), porém 
é possível que tenha sido introduzida, visto que é uma espécie de interesse ornamental e o transporte de sementes é frequente. $\mathrm{Na}$ área de estudo é morfologicamente parecida com a $D$. dissectus, por apresentarem folhas simples, profundamente lobadas. Porém, é possível distingui-las pela cor da corola, amarela e ramos glabros em $D$. tuberosus e corola branca e ramos hirsutos em $D$. dissectus. Floresce entre julho e novembro, frutifica de agosto a outubro.

Sinônimo relevante: Merremia tuberosa (L.) Rendle.

\section{Operculina Silva Manso.}

Trepadeiras, ramos alados, glabros. Folhas simples ou compostas. Pecíolo sem projeção espinescente na axila. Inflorescências cimeiras monocasiais 1-3-floras, pedunculadas. Sépalas iguais ou subiguais, glabras ou indumentadas. Corola branca ou amarela, infundibuliforme. Estames com anteras retorcidas após a antese, grãos de pólen psilados. Estilete terminal, ovário 2-locular, 4-ovulado. Cápsula com circuncisão apical, operculoide.

\section{Chave de identificação das espécies de Operculina}

1. Folhas inteiras, hastadas a cordadas; inflorescência 1-flora, corola amarela.

4.1. Operculina hamiltonii

1'. Folhas lobadas, 5-7-segmentos; inflorescência 1-3-flora, corola branca

4.2. Operculina macrocarpa

4.1. Operculina hamiltonii (G. Don) D.F. Austin \& Staples, Gen. Hist. 4: 268. $1825 . \quad$ Fig. 3a

Trepadeira lenhosa; ramos estriados, glabros; entrenós 2,3-7 cm compr. Folhas simples, 3-7,5 $\times 1,6-5,2 \mathrm{~cm}$, hastada a cordada, margem inteira, base auriculada a cordada, ápice acuminado, glabras a pubescente em ambas as faces; 5 a 7 pares de nervuras secundárias; pecíolo $0,3-2 \mathrm{~cm}$ compr., alado, pubescente. Inflorescência 1-flora; pedúnculo ca. $7 \mathrm{~cm}$ compr., glabro; pedicelo ca. $2 \mathrm{~cm}$ compr., alado, glabro; bracteólas $0,1-0,8 \times$ $0,3 \mathrm{~cm}$, lanceoladas. Sépalas subiguais, externas $2,3-2,8 \times 0,8-1,6 \mathrm{~cm}$, elípticas, base truncada, ápice cuspidado, glabras, internas $2,4-2,7 \times$ 0,8-1,1 cm, estreito-elípticas, base truncada, ápice cuspidado, glabras. Corola amarela, ca. $4,5 \mathrm{~cm}$ compr., infundibuliforme, glabra. Cápsula ca. 2 cm compr.; sementes ca. $0,8 \mathrm{~cm}$ compr., glabras.

Material examinado selecionado: Cabo de Santo Agostinho, 28.VII.2011, fl. e fr., L.R. Silva 342 (HUEFS). Paudalho, córrego do verde, 27.VII.1992, fl. e fr., A.M. Miranda et al. 525 (HST). São Lourenço da Mata, estrada da Mata, fl., D. Belo (PEUFR - 23835).

Ocorre do Caribe ao Paraguai (Staples 2010), no Brasil geralmente está presente em ambientes florestais de Mata Atlântica e Amazônia. Em Pernambuco é rara e restrita a áreas de Mata Atlântica. Operculina hamiltonni é facilmente identificada por ser a única espécie do gênero no país que apresenta folhas simples hastadas a cordadas. Em Pernambuco a espécie floresce entre junho e dezembro, frutificando de julho a novembro.
4.2. Operculina macrocarpa (L.) Urb., Syst. Nat. 10 (2): $923.1759 . \quad$ Fig. 3b

Trepadeira lenhosa; ramos estriados, glabro; entrenós 7-12 cm compr. Folhas simples, lobadas, 5-7 segmentos 7,4-8,2 × 7-16 cm, lanceoladas a elípticas, margem inteira, ápice acuminado a mucronado, glabras em ambas as faces; 8 a 12 pares de nervuras secundárias; pecíolo 2-3,5 cm compr., alado, glabro a glabrescente. Inflorescência cimeira, 1-3-flora; pedúnculo 4,6-5,8 cm compr., alado, glabro; pedicelo ca. 1,8-3,1 cm compr., alado, glabro; bracteólas 1 $\times 0,03 \mathrm{~cm}$, lanceoladas. Sépalas iguais, $2-2,3 \times$ $1,7-2 \mathrm{~cm}$, inteiras, orbiculares, base equilateral a redonda, ápice obcordado a obtuso, glabras. Corola branca, ca. $7 \mathrm{~cm}$ compr., infundibuliforme, pubescente. Cápsula ca. $2 \mathrm{~cm}$ compr.; sementes ca. $0,8 \mathrm{~cm}$, glabras.

Material examinado: Altinho, comunidade do Carão, IX.2007, fl. e fr., L.S. Sousa 216 (PEUFR). Ibimirim, estrada de barro para Petrolândia, 21.VIII.1996, fl. e fr., A.G. Silva (EAC - 40632). Salgueiro, 4.V.1984, fr., J.R. Maciel 1291 (HVASF).

Endêmica do Brasil. Em Pernambuco, apesar de não ser muito frequente, pode ser encontrada em áreas de Caatinga e Mata Atlântica (brejos de altitude). Se diferencia da $O$. hamiltonii por apresentar folhas simples lobadas, com cinco a sete segmentos, ao invés de folhas simples inteiras. Floresce entre abril e dezembro, frutifica de julho a dezembro. 


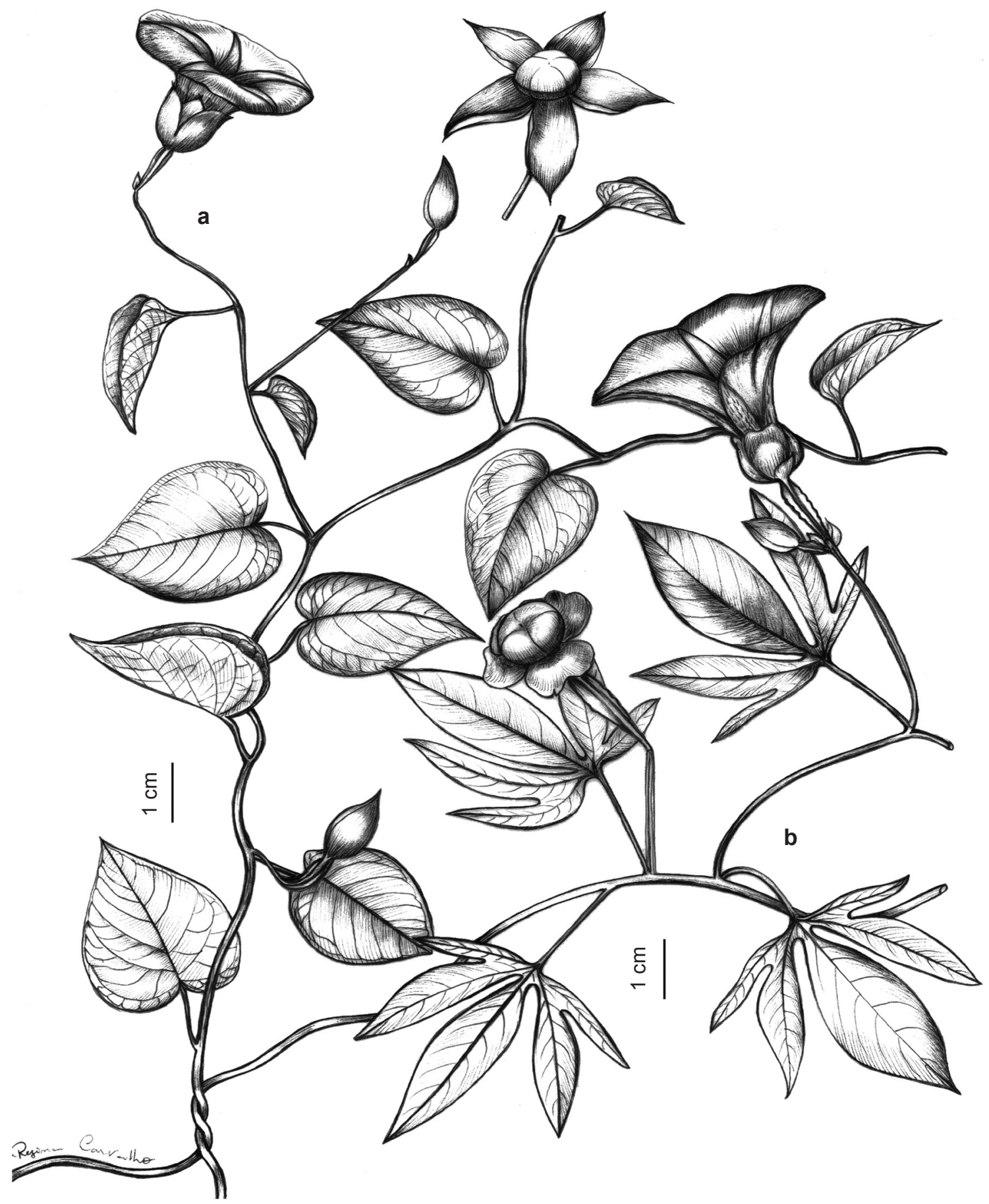

Figura 3 - a. Operculina hamiltonii - ramo florífero. b. Operculina macrocarpa - ramo florífero. Figure 3 - a. Operculina hamiltonii - fertile branch. b. Operculina macrocarpa - fertile branch. 


\section{Agradecimentos}

Os autores agradecem ao CNPq, o apoio financeiro concedido para a realização do projeto "Sistemática de Convolvulaceae da América do Sul: construir em direção ao conhecimento global" (Processo: PVE314725/2014-8); aos curadores dos herbários visitados; a Regina Carvalho, as ilustrações; e aos revisores, as contribuições ao manuscrito.

\section{Referências}

Andrade-Lima D (1960) Estudos fitogeográficos de Pernambuco. Arquivos do Instituto de Pesquisas Agronômicas 5: 305-341.

Austin DF (2007) Merremia dissecta (Convolvulaceae): condiment, medicine, ornamental and weed - a review. Economic Botany 61: 109-120.

BFG - The Brazil Flora Group (2018) Brazilian Flora 2020: innovation and collaboration to meet Target 1 of the Global Strategy for Plant Conservation (GSPC). Rodriguésia 69: 1513-1527.

Buril MT \& Alves M (2011) Flora da Usina São José, Igarassu, Pernambuco: Convolvulaceae. Rodriguésia 62: 093-105.

Buril MT, Delgado-Junior GC, Barbosa MRV \& Alves M (2013) Convolvulaceae da região do Cariri Paraibano, PB, Brasil. Revista Nordestina de Biologia 21: 3-26.

Buril MT, Simões AR, Carine M \& Alves M (2014) Austinia, a new genus of Convolvulaceae from Brazil. Phytotaxa, 186: 254 - 260.

Buril MT, Simões AR, Carine M \& Alves M (2015) Daustinia, a replacement name for Austinia (Convolvulaceae). Phytotaxa 197: 60.

Delgado-Junior GC, Buril MT \& Alves M (2014) Convolvulaceae do Parque Nacional do Catimbau, Pernambuco, Brasil. Rodriguésia 65: 261-278.

Ferreira PPA \& Miotto TS (2013) O gênero Merremia na região Sul do Brasil. Rodriguesia 64: 635-646.

Harris JG \& Harris MW (2001) Plant identification terminology: an illustrated glossary. $2^{\text {nd }}$ ed. Spring Lake, Utah. 197p.

JSTOR Plants (2016) JSTOR global plants. Disponível em $<$ http://plants.jstor.org/>. Acesso em 30 março 2017.

Lacerda MA, Silva RA, Linhares PCF, Maracajá PB \& Pinto MSC (2015) Potencial forrageiro da Jitirana
(Merremia aegyptia) para a produção de feno no semiárido nordestino. Agropecuária científica no semiárido 11: 44-52.

Lorenzi H \& Matos FJA (2002) Plantas medicinais no Brasil: nativas e exóticas. Instituto Plantarum, Nova Odessa. 512p.

Moreira ALC, Faria JEQ \& Zanatta MRV (2016) Operculina pteripes (G.Don) O'Donell (Convolvulaceae): uma nova ocorrência para o Brasil, caracterização morfológica e chave para as espécies brasileiras do gênero. Natureza On Line 14: 001-005.

Mori SA, Mattos-Silva LA, Lisboa G \& Coradin L (1985) Manual de manejo do herbário fanerogâmico. $24^{\mathrm{a}}$ ed. Centro de Pesquisas do Cacau, Ilhéus. 104p.

Nepomuceno SC, Athie-Souza SM \& Buril MT (2016) Convolvulaceae da microrregião do Alto Capibaribe, PE, Brasil. Hoehnea 43: 371-386.

O’Donell CA (1941) Revisión de las especies americanas de Merremia. Lilloa 6: 467-554.

Petrongari FS (2016) O gênero Merremia Dennst. ex Endl. (Convolvulaceae) no estado de São Paulo, Brasil. Dissertação. Instituto de Botânica, São Paulo. 152p.

Simões AR, Culham A \& Carine M (2015) Resolving the unresolved tribe: a molecular phylogenetic framework for the Merremieae (Convolvulaceae). Botanical Journal of the Linnean Society 179: 374-387.

Simões AR \& Staples G (2017) Dissolution of Convolvulaceae tribe Merremieae and a new classification the constituent genera. Botanical Journal of the Linnean Society 183: 561-586.

Staples GW (2010) Convolvulaceae unlimited. Disponível em $<$ http://convolvulaceae.myspecies. info $>$. Acesso em 16 janeiro 2019.

Staples GW \& Brummitt RK (2007) Convolvulaceae. In: Heywood VH, Brummitt RK, Culham A \& Seberg O (eds.) Flowering plant families of the world. Royal Botanic Gardens, Kew. Pp. 108-110.

Stefanović S, Austin DF \& Olmstead RG (2003) Classification of Convolvulaceae: a phylogenetic approach. Systematic Botany 28: 791- 806.

Thiers B [continuamente atualizado] Index Herbariorum: a global directory of public herbaria and associated staff. New York Botanical Garden's Virtual Herbarium. Disponível em $<$ http://sweetgum.nybg. org/science/ih/> . Acesso em 17 dezembro 2018. 


\section{Lista de exsicatas}

Alves-Araújo A 561 (1), 338 (7), 723 (7). Ataíde M 34 (4), 17 (11), 307 (11). Barreto I 7 (8). Bezerra GJ 47 (1). Belo D 207 (1), PEUFR 23835 (10). Belo D 17 (9). Belo-Moura D PEUFR 23835 (10). Buril MT 44 (3), 39 (3), 23 (4), 24 (4). Carvalho F HST 18742 (1). Carvalho-Sobrinho JG 1794 (4), 2066 (11). Castro ASF 68 (1). Coutinho TS 168 (1). Delgado-Junior GC 811 (2), 807 (4), 800 (7), 819 (7). Fontana AP 6120 (3). Garcia JD 1368 (1). Gomes A 36 (7). Gomes RCFS 2 (3). Lacerda AC HST 10114. Laurênio A 1515 (1), 1360 (4). Lima A 55 (3), IPA 7921 (6), IPA 1988 (6). Lima VC 94 (3), 365 (7). Lira OC HUEFS 68201 (5). Lucena MF 473 (1), 454 (2), 259 (3). Lucena DS 513 (7), 536 (7), 558 (7), 579 (7), 605 (7). Maciel JR 1291 (11). Meiado MV 846 (1). Mendonça ED JPB 48377 (9). Miranda AM 591 (1), 790 (3), 955 (3), 4225 (1), 5718 (4), 549 (7), 1309 (7), 525 (10), 2369 (11), 5727 (11). Oliveira ACP 1512 (4), 1884 (4). Pickel B IPA 4649 (2), IPA 4689 (5), 3084 (4), 4112 (11). Pinheiro K 157 (1). Pontual I 80 (10). Reis AMS 10 (3). Rocha EA 1568 (3). Rodrigues A 50 (7), 23 (11). Sales M 394 (7). Sampaio E 471 (7). Santos V 58 (1), 25 (4), 143 (4), 114 (7). Silva AG 14 (7), 479 (7), EAC 40632 (11). Silva FV HST 15148 (9). Silva JS 325 (3). Silva KA 578 (3). Silva LR 259 (7), 342 (10). Sobral-Leite M 1360 (7). Sousa LS 216 (11). Souza EB 54 (1). Souza ER 396 (2). Souza LGR 14 (3), 216 (11). Staples G 1719 (1), 1707 (3), 1710 (7). Viana JL 20 (7). 